\title{
Idiopathic Pericardial Effusion in Patients with Hypertrophic Cardiomyopathy
}

\author{
Sarinya Puwanant ( $\nabla$ spuwanant@gmail.com ) \\ Chulalongkorn University https://orcid.org/0000-0001-7090-9947 \\ Veraprapas Kittipibul \\ Chulalongkorn University Faculty of Medicine \\ Nattakorn Songsirisuk \\ Chulalongkorn University Faculty of Medicine \\ Sakun Santisukwongchote \\ Chulalongkorn University Faculty of Medicine \\ Patita Sitticharoenchai \\ Chulalongkorn University Faculty of Medicine \\ Pairoj Chatranukulchai \\ Chulalongkorn University Faculty of Medicine \\ Sudarat Sattithumanid \\ Chulalongkorn University Faculty of Medicine \\ Smonporn Boonyaratvej \\ Chulalongkorn University Faculty of Medicine
}

\section{Research Article}

Keywords: idiopathic pericardial effusion (i-PEF), hypertrophic cardiomyopathy (HCM), Cardiomyopathy

Posted Date: July 29th, 2021

DOI: https://doi.org/10.21203/rs.3.rs-741669/v1

License: (c) (1) This work is licensed under a Creative Commons Attribution 4.0 International License. Read Full License

Version of Record: A version of this preprint was published at The International Journal of Cardiovascular Imaging on October 12th, 2021. See the published version at https://doi.org/10.1007/s10554-021-02424-8. 


\section{Abstract}

Objectives: The aims of this study were to examine the prevalence of moderate to large (moderate-large) idiopathic pericardial effusion (i-PEF) in patients with hypertrophic cardiomyopathy (HCM) and to identify clinical and echocardiographic hemodynamic profiles associated with pericardial effusion.

Methods: A total of 292 adult patients with HCM were studied. Fifteen patients with a history of factors associated with pericardial effusion including myocardial infarction, heart surgery or cardiac procedure within the last 12 months, autoimmune disease, hydralazine use, chronic kidney disease stage 3-4, tuberculosis, and malignancy were excluded.

Results: Of 277 eligible patients with $\mathrm{HCM}, 11$ patients (4\%) with moderate-large i-PEF were identified. Clinical tamponade was present in 1 patient. Compared to patients with HCM who had no or small pericardial effusion, patients with moderate-large i-PEF were younger and more likely to have right ventricular (RV) hypertrophy and reverse septal curvature. These patients also exhibited a greater maximal septal thickness, mean and systolic pulmonary pressure, and right atrial pressure $(p<0.05$ for all). Pericardial fluid analysis and histopathological exams were performed in 7 and 3 patients, respectively. All examinations revealed transudative and nonspecific etiology of pericardial effusion.

Conclusions: Idiopathic pericardial effusion and cardiac tamponade in patients with HCM was uncommon. The pathophysiology involved in pericardial effusion remains undetermined. Patients with moderate-large i-PEF frequently exhibited a phenotype of pulmonary hypertension and RV pressure overload.

\section{Introduction}

Pericardial effusion is a common disorder in clinical practice. ${ }^{(1 ; 2 ; 3)}$ The common etiologies of pericardial effusion include infection, malignancy, connective tissue disease, immune process, myopericarditis, uremic, hypothyroidism, hydropericardium syndrome, or hemopericardium syndrome. ${ }^{(1 ; 2 ; 3)}$ Recently, we observed patients with hypertrophic cardiomyopathy $(\mathrm{HCM})$ who presented with moderate to large pericardial effusion of unknown etiology. The prevalence and clinical significance of pericardial effusion in patients with hypertrophic cardiomyopathy (HCM) has not been widely investigated. The aims of this study were to examine the prevalence of idiopathic pericardial effusion in patients with HCM and to identify clinical and echocardiographic characteristics associated with moderate to large pericardial effusion.

\section{Methods Study patients}

The study protocol was approved by the Chulalongkorn University Institutional Review Board (IRB). A total of 292 adult ( $\geq 18$ years old) patients with HCM were reviewed for enrollment. Patients with a history of myocardial infarction within the last 12 months $(n=8)$, heart surgery or ablative procedure prior to cardiac imaging study $(n=1)$, autoimmune disease $(n=2)$, hydralazine use $(n=1)$, acute pericarditis/myocarditis $(n=0)$, tuberculosis $(n=1)$, malignancy $(n=$ 1), HIV infection $(n=0)$, and chronic kidney disease stage 3-4 $(n=1)$ were excluded. A total of 277 patients were included in the study. Hypertrophic cardiomyopathy (HCM) was diagnosed based on echocardiographic evidence of left ventricular (LV) hypertrophy in the absence of other explainable causes of hypertrophy(4)

\section{Echocardiography}

Comprehensive echocardiogram was performed in all patients using commercially available ultrasound machines, Vivid 7 GE-Vingmed (Milwaukee, WI), IE-33 Philips (Philips Medical System, Andover, Mass), and ProSound Alpha 10 (Hitachi Aloka Medical. Ltd., Tokyo, Japan). Respiratory variation of echocardiographic parameters was assessed by respirometer during echocardiographic examination in patients with pericardial effusion $\geq 2 \mathrm{~cm}$ or suspicion of cardiac tamponade. Echocardiographic images were digitally stored in EchoPAC and QLAB software package for off-line analysis. Asymmetrical septal hypertrophy (ASH) was defined as septal-to-free-wall ratio of $\geq 1.3$. ${ }^{(4)}$ Apical HCM including pure and mixed apical HCM (apical/septal) was defined as previously described $(5 ; 6) .15,16$ Septal morphology subtypes were classified as sigmoid, reverse-curve, neutral, and apical variant as previously described ${ }^{(7)}$. Pericardial effusion, an echo-free space visualized between parietal and visceral pericardium at end diastole, was semi-quantitatively classified as trivial (present in only systole), small $(<1 \mathrm{~cm})$, moderate $(1-2 \mathrm{~cm})$, large $(>2 \mathrm{~cm})$, or very large/massive $(>2.5 \mathrm{~cm})$. (2) Right ventricular (RV) systolic and diastolic echocardiographic parameters were assessed according to the guidelines for echocardiographic assessment of the right heart in adults endorsed by the EAE and the Canadian Society of Echocardiography. ${ }^{(8)}$ Pulmonary arterial systolic pressure in the absence of pulmonary stenosis was estimated by the peak continuous-wave Doppler of the tricuspid regurgitation velocity with $4 \mathrm{~V}^{2}$ plus right atrial pressure estimated from inferior vena caval (IVC) size and its collapsibility. $\left.{ }^{8 ;} ; ; 10\right)$ Mean pulmonary arterial pressure was estimated by the peak continuous-wave Doppler of the pulmonary regurgitation velocity as $4 \mathrm{~V}^{2}$ plus right atrial pressure estimated from IVC size and its collapsibility. ${ }^{(11)}$ Pulmonary hypertension (PH) was defined as estimated pulmonary arterial systolic pressure $>35 \mathrm{mmHg}$.

\section{Pathological examination}

Pericardial and myocardial pathological specimens were fixed in formalin and paraffin embedded in patients who underwent pericardial or endomyocardial biopsy or surgical myectomy. The surgical specimens of pericardium and myocardium were stained with hematoxylin and eosin and Movat pentachrome. Pericardial specimens were additionally stained with acid fast bacilli (AFB) and modified AFB and cultured for aerobe, anaerobic, tuberculosis, and fungal organisms. Gross pericardial specimens were measured for maximal thickness. Pericardial histopathological slides were reviewed by an expert cardiac pathologist for the presence of calcification, fibrosis, inflammation, caseous and non-caseous granulomas, mesothelial abnormalities, hemosiderin deposition, and malignancy. Myocardial histopathological slides were examined for myocyte hypertrophy and disarray, dysplastic intramural coronary arterioles with 
medial and intimal thickening, and fibrosis. Myocardial specimens were additionally stained for Congo red and periodic acid-Schiff to exclude cardiac amyloidosis and glycogen storage disease. Surgical myectomy and endomyocardial biopsy were performed in 34 and 2 patients, respectively. Myocardial histopathological specimens from surgical myectomy in 36 patients confirmed HCM.

\section{Statistical analysis}

Categorical data are presented as frequency and percentage. Continuous data are expressed as mean \pm standard deviation (SD). Differences in means were compared by Student's t test for variables with normal distribution and Wilcoxon-rank sum test for variables with non-normal distribution. Categorical variables were compared using chi's square test or Fischer's exact test, where appropriate. Due to small numbers of patients with moderate and large pericardial effusion, multivariate analysis was not performed. A $p$ value $<0.05$ was considered significant.

\section{Results}

Clinical and echocardiographic characteristics

Among the 277 eligible patients with $\mathrm{HCM}, 11$ patients (4\%) with moderate to large idiopathic pericardial effusion were identified. Moderate and large pericardial effusion was found in 7 and 4 patients, respectively. Clinical tamponade was present in 1 patient, while echocardiographic tamponade was present in 2 patients. An additional 14 (5\%) patients exhibited small pericardial effusion. (Fig. 1) Baseline characteristics of patients are shown in Table 1. Compared to patients with $\mathrm{HCM}$ who had no or small pericardial effusion, patients with moderate to large idiopathic pericardial effusion were younger (49 \pm 16 vs. $63 \pm$ 16 years; $p=0.01)$. Significant clinical differences included being more likely to have pulmonary hypertension $(90 \%$ vs. $40 \% ; p<0.01)$ and reverse septal curvature ( $72 \%$ vs. $29 \%$; $=0.02)$, a greater maximal septal thickness $(24 \pm 5$ vs. $18 \pm 5 \mathrm{~mm}$.; $p<0.01)$, higher RV free wall thickness $(10 \pm 2$ vs. $8 \pm 3$ mm; $p<$ $0.01)$, higher mean pulmonary pressure ( $29 \pm 5 \mathrm{vs} .22 \pm 6 \mathrm{mmHg} ; \mathrm{p}<0.01)$, higher systolic pulmonary pressure (48 $\pm 11 \mathrm{vs}$. $36 \pm 11 \mathrm{mmHg} ; \mathrm{p}<0.01)$, and higher right atrial pressure $(15 \pm 5$ vs. $6 \pm 4 \mathrm{~mm} ; \mathrm{p}<0.01)$. Figure $2 \mathrm{~A}$ and video A illustrate a large pericardial effusion identified on transthoracic echocardiogram in a patient with HCM (Patient \#4 in Table 2). Figure 2B illustrates a massive circumferential pericardial effusion and normal pericardial findings identified on cardiovascular magnetic resonance imaging in the same patient (Fig. 2B). 
Table 1

Clinical and echocardiographic characteristics by presence or absence of moderate to large pericardial effusion.

\begin{tabular}{|c|c|c|c|c|}
\hline & $\begin{array}{l}\text { All } \\
(n=277)\end{array}$ & $\begin{array}{l}\text { Moderate to Large Pericardial } \\
\text { Effusion } \\
(n=11)\end{array}$ & $\begin{array}{l}\text { Non-significant Pericardial } \\
\text { Effusion } \\
(n=266)\end{array}$ & $\begin{array}{l}P \\
\text { value }\end{array}$ \\
\hline Age & $63 \pm 16$ & $49 \pm 16$ & $63 \pm 16$ & $0.01^{*}$ \\
\hline Female & $\begin{array}{l}161 \\
(58 \%)\end{array}$ & $6(55 \%)$ & $155(58 \%)$ & 0.81 \\
\hline NYHA Class III-IV [n (\%)] & $48(17 \%)$ & $2(18 \%)$ & $46(18 \%)$ & 0.16 \\
\hline Systolic blood pressure (mmHg) & $130 \pm 19$ & $131 \pm 20$ & $130 \pm 19$ & 0.88 \\
\hline Diastolic blood pressure $(\mathrm{mmHg})$ & $74 \pm 11$ & $74 \pm 6$ & $75 \pm 11$ & 0.50 \\
\hline Atrial fibrillation [n (\%)] & $36(13 \%)$ & $1(9 \%)$ & $35(13 \%)$ & 0.69 \\
\hline $\begin{array}{l}\text { Major Phenotype [n (\%)] } \\
\text { - Asymmetrical septal hypertrophy } \\
\text { - Pure apical } \\
\text { - Mixed apical } \\
\text { - Concentric } \\
\text { - Localized/Mid }\end{array}$ & $\begin{array}{l}138 \\
(50 \%) \\
56(20 \%) \\
30(11 \%) \\
47(17 \%) \\
6(2 \%)\end{array}$ & $\begin{array}{l}8(73 \%) \\
2(18 \%) \\
0 \\
1(9 \%) \\
0\end{array}$ & $\begin{array}{l}130(49 \%) \\
54(20 \%) \\
30(12 \%) \\
46(17 \%) \\
6(2 \%)\end{array}$ & 0.68 \\
\hline Reverse-curve septal morphology & $86(31 \%)$ & $8(72 \%)$ & $78(29 \%)$ & $0.02^{\star}$ \\
\hline Large pericardial effusion & $4(1 \%)$ & $4(36 \%)$ & 0 & $<0.01^{*}$ \\
\hline Beta blocker [n (\%)] & $\begin{array}{l}121 \\
(73 \%)\end{array}$ & $11(100 \%)$ & $197(74 \%)$ & 0.05 \\
\hline Calcium channel blocker [n (\%)] & $39(14 \%)$ & $1(9 \%)$ & $38(14 \%)$ & 0.62 \\
\hline Septal myectomy [n (\%)] & $34(12 \%)$ & $6(54 \%)$ & $28(10 \%)$ & $<0.01^{*}$ \\
\hline Alcohol septal ablation [n (\%)] & $2(1 \%)$ & $0(0 \%)$ & $2(1 \%)$ & 0.77 \\
\hline Maximal septal thickness (mm) & $19 \pm 5$ & $24 \pm 5$ & $18 \pm 5$ & $<0.01^{*}$ \\
\hline Resting LVOT gradient > 30 mmHg [n (\%)] & $60(36 \%)$ & $3(33 \%)$ & $57(35 \%)$ & 0.88 \\
\hline LVEDD (mm) & $43 \pm 8$ & $41 \pm 9$ & $43 \pm 8$ & 0.77 \\
\hline LVEF (\%) & $71 \pm 12$ & $71 \pm 13$ & $71 \pm 12$ & 0.88 \\
\hline LAVI (ml/m2) & $39 \pm 16$ & $39 \pm 13$ & $39 \pm 17$ & 0.99 \\
\hline RAVI (ml/m2) & $33 \pm 16$ & $40 \pm 24$ & $33 \pm 15$ & 0.42 \\
\hline RV free wall thickness (mm) & $9 \pm 3$ & $10.3 \pm 2.0$ & $8.4 \pm 2.7$ & $0.01^{*}$ \\
\hline Estimated RAP (mmHg) & $7 \pm 4$ & $15 \pm 5$ & $6 \pm 4$ & $<0.01^{*}$ \\
\hline $\begin{array}{l}\text { Estimated pulmonary arterial systolic pressure } \\
(\mathrm{mmHg})\end{array}$ & $36 \pm 11$ & $48 \pm 11$ & $36 \pm 11$ & $<0.01^{*}$ \\
\hline $\begin{array}{l}\text { Estimated mean pulmonary arterial pressure } \\
(\mathrm{mmHg})\end{array}$ & $22 \pm 6$ & $29 \pm 5$ & $22 \pm 6$ & $<0.01^{*}$ \\
\hline Pulmonary hypertension (n,\%) & $\begin{array}{l}117 \\
(42 \%)\end{array}$ & $10(90 \%)$ & $107(40 \%)$ & $<0.01^{*}$ \\
\hline TAPSE (mm) & $17.9 \pm 4.6$ & $18.3 \pm 4.3$ & $18.0 \pm 4.6$ & 0.76 \\
\hline
\end{tabular}


Table 2

Clinical and cardiac imaging characteristics of HCM patients with pericardial effusion

\begin{tabular}{|c|c|c|c|c|c|c|c|c|c|c|c|c|}
\hline $\begin{array}{l}\text { Patient } \\
\text { no. }\end{array}$ & $\begin{array}{l}\text { Age/ } \\
\text { Gender }\end{array}$ & $\begin{array}{l}\text { Effusion } \\
(\mathrm{mm})\end{array}$ & Effusion & $\begin{array}{l}\mathrm{EF} \\
(\%)\end{array}$ & $\begin{array}{l}\text { RV free } \\
\text { wall } \\
\text { thickness } \\
(\mathrm{mm})\end{array}$ & $\begin{array}{l}\text { Maximal } \\
\text { thickness }\end{array}$ & $\begin{array}{l}\text { Resting } \\
\text { LVOT } \\
\text { gradient }\end{array}$ & Phenotype & $\begin{array}{l}\text { RAP } \\
(\mathrm{mmHg})\end{array}$ & $\begin{array}{l}\text { RVSP } \\
(\mathrm{mmHg})\end{array}$ & $\begin{array}{l}\text { Pathological } \\
\text { Exam }\end{array}$ & $\begin{array}{l}\text { Pericardial } \\
\text { fluid color }\end{array}$ \\
\hline 1 & $57 \mathrm{~F}$ & 17 & Moderate & 84 & 9.4 & 32 & 19 & $\mathrm{ASH}$ & 18 & 44 & $\begin{array}{l}\text { Not } \\
\text { performed }\end{array}$ & $\begin{array}{l}\text { Straw, } \\
\text { clear }\end{array}$ \\
\hline 2 & $71 \mathrm{M}$ & 36 & Large & 73 & 9.0 & 19 & 20 & ASH & 20 & 72 & Normal & $\begin{array}{l}\text { Straw, } \\
\text { clear }\end{array}$ \\
\hline 3 & $24 \mathrm{~F}$ & 13 & Moderate & 87 & 11.3 & 19 & 63 & ASH & 8 & 54 & $\begin{array}{l}\text { Not } \\
\text { performed }\end{array}$ & N/A \\
\hline 4 & $40 \mathrm{M}$ & 30 & Large & 90 & 13.0 & 31 & 40 & ASH & 20 & 39 & Normal & $\begin{array}{l}\text { Straw, } \\
\text { clear }\end{array}$ \\
\hline 5 & $54 \mathrm{M}$ & 12 & Moderate & 70 & 9.1 & 21 & 12 & Apical & 10 & 31 & $\begin{array}{l}\text { Not } \\
\text { performed }\end{array}$ & $\mathrm{N} / \mathrm{A}$ \\
\hline 6 & $56 \mathrm{M}$ & 26 & Large & 76 & 7.0 & 30 & 18 & Apical & 15 & 49 & $\begin{array}{l}\text { Not } \\
\text { performed }\end{array}$ & $\begin{array}{l}\text { Straw, } \\
\text { clear }\end{array}$ \\
\hline 7 & $51 \mathrm{M}$ & 14 & Moderate & 65 & 9.2 & 22 & 23 & Concentric & 20 & 42 & $\begin{array}{l}\text { Not } \\
\text { performed }\end{array}$ & $\mathrm{N} / \mathrm{A}$ \\
\hline 8 & $21 \mathrm{~F}$ & 13 & Moderate & 45 & 10.0 & 21 & 15 & ASH & 15 & 51 & $\begin{array}{l}\text { Not } \\
\text { performed }\end{array}$ & $\mathrm{N} / \mathrm{A}$ \\
\hline 9 & $47 \mathrm{~F}$ & 23 & Large & 61 & 13.1 & 29 & 14 & ASH & 15 & 58 & Normal & $\begin{array}{l}\text { Straw, } \\
\text { clear }\end{array}$ \\
\hline 10 & $52 \mathrm{~F}$ & 15 & Moderate & 68 & 12.0 & 20 & 25 & ASH & 15 & 53 & $\begin{array}{l}\text { Not } \\
\text { performed }\end{array}$ & $\begin{array}{l}\text { Straw, } \\
\text { clear }\end{array}$ \\
\hline 11 & $67 \mathrm{M}$ & 16 & Moderate & 65 & 11.0 & 22 & 66 & ASH & 3 & 39 & $\begin{array}{l}\text { Not } \\
\text { performed }\end{array}$ & $\begin{array}{l}\text { Straw, } \\
\text { clear }\end{array}$ \\
\hline
\end{tabular}

ASH: Asymmetrical septal hypertrophy; EF: Ejection fraction; F: female; LVOT: left ventricular outflow tract; M: male; mm: millimeter; MRI: magnetic resonance ventricular; RVSP: right ventricular systolic pressure; S: systolic forward flow; TB: tuberculosis.

Pericardial Fluid Analysis and Pathological Examination

Table 2 shows clinical, cardiac imaging, and pericardial characteristics in patients with moderate to large pericardial effusion. Among those with large pericardial effusion, pericardial histopathological exams were performed in 3 patients with massive pericardial effusion. Findings of these patients revealed normal pericardial thickening with no active inflammation. Mesothelial cells were intact. No granuloma, malignancy or calcification was visualized. Pericardial fluid analysis was performed in 7 patients with moderate to large pericardial effusion with all revealed as transudative. Pericardial-fluid and tissue stains for AFB and modified AFB were all negative for tuberculosis and nocardia. Pericardial fluid and tissue cultures for aerobe, anaerobe, and fungus were negative. Pericardial fluid and tissue cultures and polymerase chain reaction (PCR) for tuberculosis were also negative. Pericardial fluid cytology was negative for malignancy. Figure 3 illustrates pathological findings of pericardium in patient \#4 (Table 2) who underwent surgical myectomy and pericardial biopsy.

\section{Discussion}

This study is the first to examine the prevalence of idiopathic pericardial effusion among those with HCM and the clinical and pericardial pathological profiles of these patients. The major findings of the study are: (1) prevalence of moderate to large pericardial effusion in patients with HCM was $4 \%$ (11/277); (2) pericardial pathological and fluid analysis in patients with massive pericardial effusion were characterized by normal pericardial thickening, nonspecific histological findings, and transudative profile with no evidence of infectious or inflammatory process, or autoimmune or inflammatory reactive etiology; and (3) patients with moderate to large pericardial effusion were more likely to have pulmonary hypertension (PH), elevated right atrial pressure, right ventricular hypertrophy and septal hypertrophy.

The normal pericardial sac contains $20-50 \mathrm{ml}$ of pericardial fluid. ${ }^{(1 ; 2)}$ A pericardial effusion occurs when excess pericardial fluid accumulates in the pericardial sac. ${ }^{(1 ; 2)}$ Pericardial fluid is normally generated by plasma ultrainfiltrate and drains to the mediastinal, tracheobronchial, peri-esophageal and pleural lymphatic systems. ${ }^{(2)}$ The excessive pericardial fluid is typically caused by (1) increased production of pericardial fluid following infectious or noninfectious inflammatory pericardial process (mostly exudate), (2) impaired reabsorption or drainage of pericardial fluid (transudate) including heart failure or $\mathrm{PH}$, (3) systemic conditions including hypoalbuminemia or hypothyroidism (transudate/hydropericardium), or (4) conditions associated with cardiac and great-vessel injuries (hemopericardium). ${ }^{(2 ; 3 ; 12)}$ In our study, the prevalence of moderate to large pericardial effusion in patients with HCM was uncommon (4\% of patients with $\mathrm{HCM}$ ). We found that no inflammatory, infectious, or specified etiologies were identified in these patients. Patients with moderate to large pericardial effusion did have higher estimated right atrial and pulmonary arterial pressures compared to those with no or small pericardial effusion. The pathogenesis of pericardial effusion in $\mathrm{PH}$ is currently unclear. Previous studies have reported $15-65 \%$ of patients with $\mathrm{PH}$ had pericardial effusion. ${ }^{(12 ; 13 ;}$;4) Hinderliter et al. demonstrated that severity of RV dysfunction is associated with pericardial effusion in patients with $\mathrm{PH}$, and among invasive intracardiac and 
pulmonary hemodynamic indices, mean right atrial pressure correlated best with the size of pericardial effusion. ${ }^{(15)}$ Fröhlich et al. suggested that venous and/or lymphatic congestion may be involved in the etiology of pericardial effusion in heart failure. ${ }^{(14)}$ Further, they proposed that cytokines released in severe heart failure may play a role in the instigation of pericardial effusion by way of systemic inflammatory inducing capillary leakage which increase production of pericardial effusion. Ong et al. reported that $38 \%$ of patients with $\mathrm{HCM}$ had $\mathrm{PH}$. In our study, $42 \%$ of overall patients with $\mathrm{HCM}$ and $90 \%$ of patients with moderate to large pericardial effusion had PH. Whether pericardial effusion was coincident or associated with HCM remains to be determined. We hypothesize that right heart congestion and/or PH may be involved in the pathophysiology of idiopathic pericardial effusion in patients with HCM. Additionally, we found that patients with moderate to large pericardial effusion had greater septal thickness and were more likely to undergo surgical myectomy. This finding supports the link between the degree of LV wall thickness, diastolic dysfunction, and $\mathrm{PH} .{ }^{(16)}$

To our best knowledge, there has been no systematic review or published data about idiopathic pericardial effusion or tamponade in HCM patients. This study is the first to describe the clinical and pericardial pathological profiles in an HCM cohort. The severity of pericardial effusion along with the severity of right atrial and pulmonary pressures in both patients with pericardial pathological confirmation confirms a similar trend of findings among the entire cohort.

\section{Study Limitations}

Pericardial biopsy or pericardiocentesis was not performed in all patients with pericardial effusion. Traditionally, patients with HCM with small to moderate pericardial effusion with no clinical tamponade do not require invasive biopsy or pericardiocentesis. Simultaneous invasive pulmonary pressure and vascular resistance measurements were not performed in all patients with pericardial effusion and $\mathrm{PH}$. Doppler interrogation of tricuspid regurgitation to estimate peak pulmonary arterial systolic pressure has been validated and widely accepted and remains the best noninvasive measure available. ${ }^{(9 ; 10)}$

\section{Conclusions}

Idiopathic moderate to large pericardial effusion was found uncommon and occurred in only $4 \%$ of patients with HCM. All patients with a completed pericardial fluid analysis showed transudative profiles. Whether pericardial effusion was coincident or associated with HCM remains undetermined. Since patients with moderate to large pericardial effusion exhibited greater septal thickness, pulmonary pressure, and RV free wall thickness, we suggest that PH may be involved in the pathophysiology of pericardial effusion in patients with HCM.

\section{Declarations}

Disclosure. None.

Prior presentation/publication: None

Grants: This work was partially supported by RatchadaphiseksompotEndowment Fund\#24/53 (Dr. Puwanant).

Conflict of interest for all authors: none

\section{References}

1. Tjaik AJ (1977) Echocardiography in pericardial effusion. Am J Med 63:29-40

2. Klein AL, Abbara S, Agler DA et al (2013) American Society of Echocardiography clinical recommendations for multimodality cardiovascular imaging of patients with pericardial disease: endorsed by the Society for Cardiovascular Magnetic Resonance and Society of Cardiovascular Computed Tomography. Journal of the American Society of Echocardiography: official publication of the American Society of Echocardiography 26:965-1012.e1015

3. Maisch B, Seferovic PM, Ristic AD et al (2004) Guidelines on the diagnosis and management of pericardial diseases executive summary; The Task force on the diagnosis and management of pericardial diseases of the European society of cardiology. European heart journal 25:587-610

4. Elliott P, Andersson B, Arbustini E et al (2008) Classification of the cardiomyopathies: a position statement from the European Society Of Cardiology Working Group on Myocardial and Pericardial Diseases. European heart journal 29:270-276

5. Kim EK, Lee SC, Hwang JW et al (2016) Differences in apical and non-apical types of hypertrophic cardiomyopathy: a prospective analysis of clinical, echocardiographic, and cardiac magnetic resonance findings and outcome from 350 patients. Eur Heart J Cardiovasc Imaging 17:678-686

6. Klarich KW, Attenhofer Jost CH, Binder J et al (2013) Risk of death in long-term follow-up of patients with apical hypertrophic cardiomyopathy. The American journal of cardiology 111:1784-1791

7. Binder J, Ommen SR, Gersh BJ et al (2006) Echocardiography-guided genetic testing in hypertrophic cardiomyopathy: septal morphological features predict the presence of myofilament mutations. Mayo Clinic proceedings $\mathbf{8 1}, 459-467$

8. Rudski LG, Lai WW, Afilalo J et al (2010) Guidelines for the echocardiographic assessment of the right heart in adults: a report from the American Society of Echocardiography endorsed by the European Association of Echocardiography, a registered branch of the European Society of Cardiology, and the Canadian Society of Echocardiography. Journal of the American Society of Echocardiography: official publication of the American Society of Echocardiography 23:685-713; quiz 786 - 688

9. Currie PJ, Seward JB, Chan KL et al (1985) Continuous wave Doppler determination of right ventricular pressure: a simultaneous Doppler-catheterization study in 127 patients. J Am Coll Cardiol 6:750-756

10. Kircher BJ, Himelman RB, Schiller NB (1990) Noninvasive estimation of right atrial pressure from the inspiratory collapse of the inferior vena cava. The American journal of cardiology 66:493-496 
11. Abbas AE, Fortuin FD, Schiller NB et al (2003) Echocardiographic determination of mean pulmonary artery pressure. The American journal of cardiology 92:1373-1376

12. Imazio M, Adler Y (2013) Management of pericardial effusion. European heart journal 34:1186-1197

13. Fenstad ER, Le RJ, Sinak LJ et al (2013) Pericardial effusions in pulmonary arterial hypertension: characteristics, prognosis, and role of drainage. Chest 144:1530-1538

14. Frohlich GM, Keller P, Schmid F et al (2013) Haemodynamically irrelevant pericardial effusion is associated with increased mortality in patients with chronic heart failure. European heart journal 34:1414-1423

15. Hinderliter AL, Willis PWt, Long W et al (1999) Frequency and prognostic significance of pericardial effusion in primary pulmonary hypertension. PPH Study Group. Primary pulmonary hypertension. The American journal of cardiology $84,481-484$, a 410

16. Ong KC, Geske JB, Hebl VB et al (2016) Pulmonary hypertension is associated with worse survival in hypertrophic cardiomyopathy. Eur Heart $J$ Cardiovasc Imaging 17:604-610

\section{Figures}

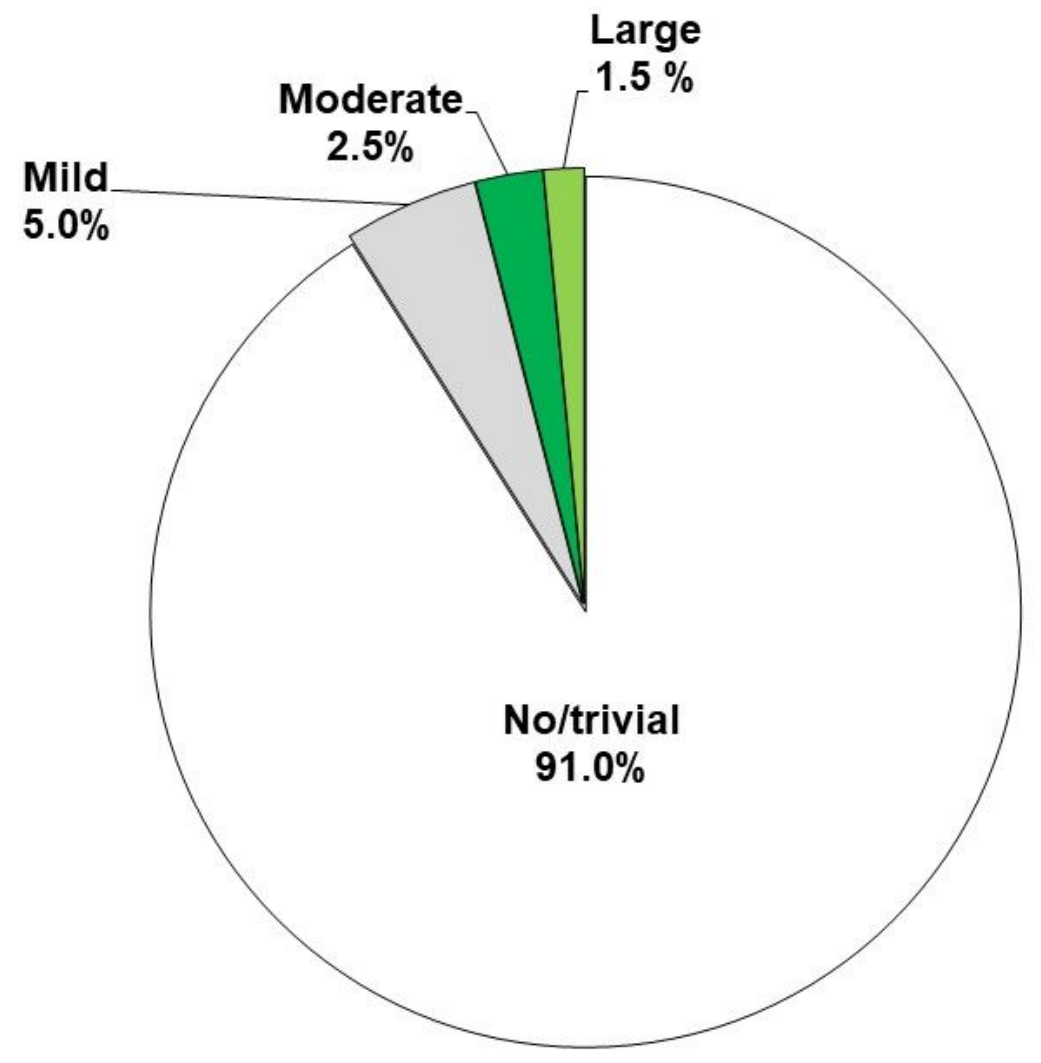

Figure 1

The prevalence of idiopathic pericardial effusion in patients with HCM. 

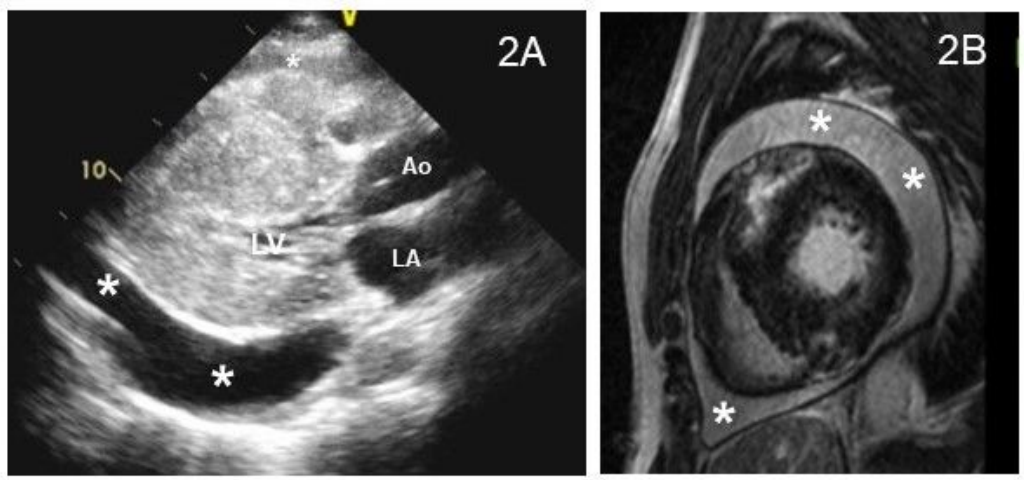

Figure 2

A massive circumferential pericardial effusion (asterisks) in a 40-year-old man with a hypertrophic cardiomyopathy (patient \#2) demonstrated by transthoracic echocardiogram (2A) and cardiovascular magnetic resonance imaging (2B).

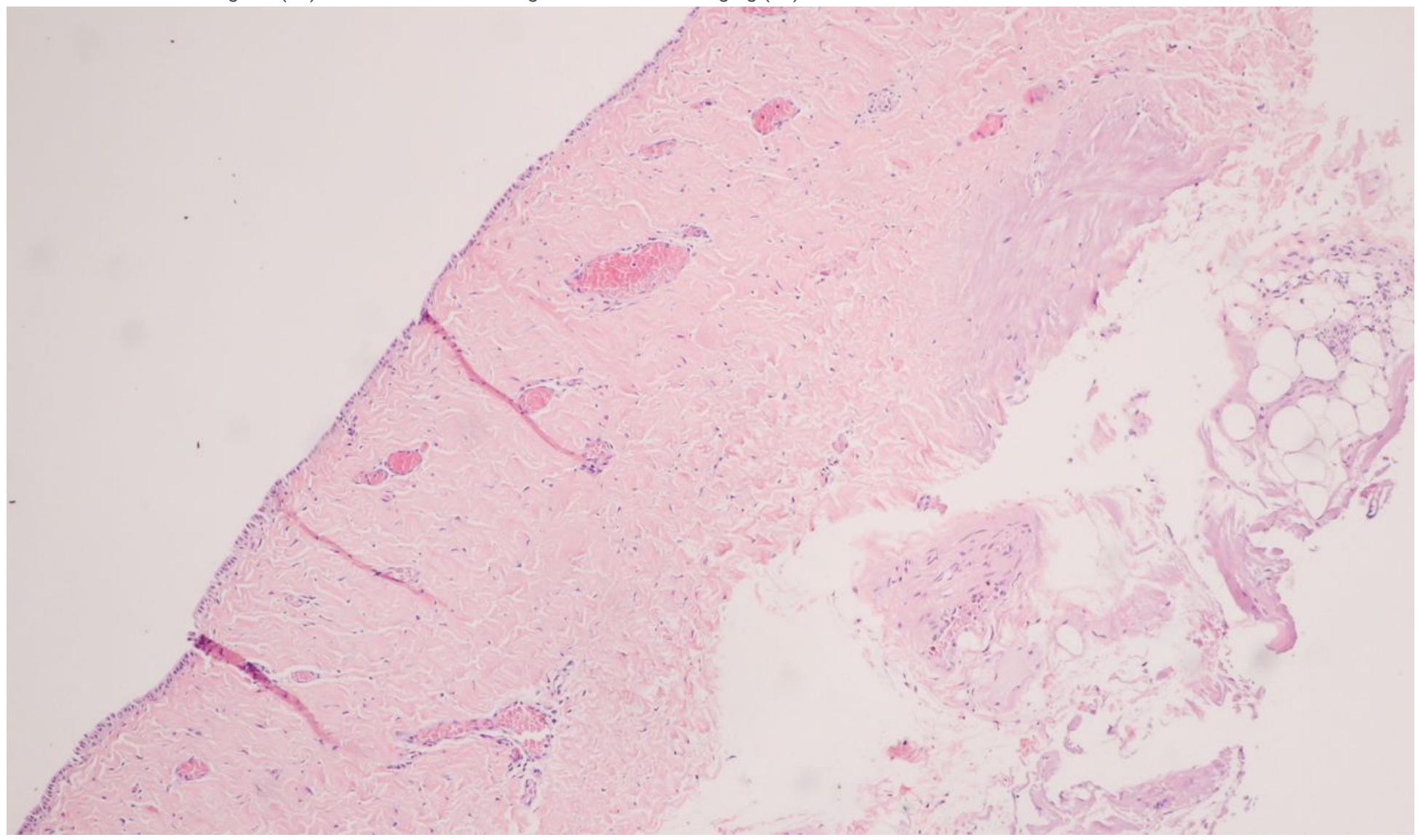

\section{Figure 3}

Example of pericardial histopathological findings of a 40-year-old patient who underwent surgical myectomy and pericardial biopsy. The pericardium revealed normal pericardial thickening and intact mesothelial cells with no active inflammation, granuloma, malignancy, or calcification.

\section{Supplementary Files}

This is a list of supplementary files associated with this preprint. Click to download.

- VDOAandB.mp4 